\title{
Standardized versus Unstandardized Regression Weights
}

\author{
James M. Richards, Jr. \\ The Johns Hopkins University
}

\begin{abstract}
Behavioral scientists appear widely divided about the merits of standardized versus unstandardized regression weights. The present paper has therefore attempted to clarify the issue by illustrating how the two kinds of weights respond to the following circumstances: selection, or sampling variation, on the independent variable; presence of measurement error; changes in units of measurement; scales that are relative to norms rather than absolute; changes in test length; and selection on dependent and mediating variables. Standardized weights are invariant over changes in the units of measurement; unstandardized weights are invariant over selection on the independent variable (but only on the independent variable) and in the presence of dependent variable error. In general, however, the illustrated circumstances affected both kinds of weights, sometimes quite strongly. Therefore, neither kind of weight appears very robust, neither can be recommended unequivocally for comparing groups, and neither provides a panacea for overcoming problems of analyzing behavioral data.
\end{abstract}

Behavioral scientists appear widely divided, and perhaps somewhat confused, about the relative merits of standardized and unstandardized regression weights. Because a preference for unstandardized weights appears dominant among sociologists while a preference for standardized weights appears dominant among psychologists, this division could act as a substantial barrier to

APPLIED PSYCHOLOGICAL MEASUREMENT Vol. 6, No. 2, Spring 1982, pp. 201-212

(c) Copyright 1982 Applied Psychological Measurement Inc. 0146-6216/82/020201-12\$1.60 communication across disciplines. Accordingly, the present review was undertaken to clarify the standardized versus unstandardized weights issue by presenting some simple, concrete examples of how these weights behave in various circumstances. The theoretical relationships underlying these examples are well known (Gulliksen, 1950); but they rarely, if ever, have been used to compare standardized and unstandardized weights. Therefore, although the present paper is aimed primarily at practicing researchers, the examples may also be informative to methodologists and theoreticians.

All of the examples presented here involve least squares regression equations and random variable regression; but the principles involved are equally applicable to weights computed by other procedures, such as maximum likelihood, and to fixed variable regression. Many of the situations described here are less likely to arise, however, in the experimental context typical of fixed variable regression. (Gulliksen, 1950, has presented the mathematics underlying these examples in detail, so his equations and derivations are not repeated here.)

This review is divided into four sections. The first section explores the reasons why some behavioral scientists prefer unstandardized weights. The second examines the reasons other behavioral scientists prefer standardized weights. The third section examines situations 
that do not fit conveniently under the rubric of comparing perspectives on regression weights, and the concluding section considers the implications of these analyses.

\section{Why Do Some Behmvioral Scientists Prefer Unastand}

Bohrnstedt (1969) provided the following representative example of the major argument for preferring unstandardized regression weights:

The regression coefficient is suggested as more appropriate than the correlation coefficient or the standardized coefficient since the unstandardized coefficient is relatively stable across subsamples of the population whereas the standardized coefficients ... may vary significantly as a function of the standard deviations.

The meaning of such statements can be clarified by considering the familiar example of college admissions. Studying the relationship between high-school and college grade-point averages (GPAs) is problematical, because students are chosen largely on the basis of high-school grades. In the pure case, students falling below some minimum GPA are denied admission to college, thus truncating the distribution of highschool GPAs. Such truncation directly reduces the standard deviation of high-school GPAs and indirectly reduces both the correlation between high-school and college GPAs and the standard deviation of college GPAs (Gulliksen, 1950). These effects would be substantially greater at more competitive colleges, so such truncation is an extreme case of the kind of yariation in standard deviations cited by proponents of unstan. dardized weights (Blalock, 1964, 1967, 1968, 1976; Bohrnstedt, 1969; Duncan, 1975; Kim \& Mueller, 1976; Schoenberg, 1972).

It is customary in psychometric literature to refer to this process as "selection"; to call the variable (or variables) on which cases are chosen (in this example, high-school grades) the "explicit selection" variable; and to call the variable (or variables) that is indirectly affected (in this example, college grades) the "incidental selection" variable. A selection framework appears especially useful for examining the properties of unstandardized and standardized weights, but the mathematics are completely general to differences in standard deviations produced by simple sampling variation. It still would be useful, however, to distinguish between "explicit sampling" variables and "incidental sampling" variables.

Accordingly, the first example involves data for the relationship between high-school and college GPAs. Although these data are entirely hypothetical, values were chosen to be close to the values suggested by compendia (e.g., American College Testing Program, 1966). Formulas presented by Gulliksen (1950, pp. 128-144) were used to compute the impact on standardized and unstandardized regression weights of various degrees of explicit selection on high-school GPAs. These formulas require knowledge of the standard deviation of the selected group on the explicit selection variable, so such standard de. viations were computed from the table of randomly distributed cases presented by Ghiselli (1964). Results are presented in Table 1, with the left column of this table representing the underlying true or population values. It should be emphasized that these results would occur whether or not high-school GPAs "cause" college GPAs.

The most important trends in this table are that explicit selection on high-school GPA reduced the correlation between school and college GPAs, and therefore the standardized regression weights, while the unstandardized regression weights were invariant under such selection. This invariance is just the property of unstandardized weights cited by Bohrnstedt (1969) that underlies most of the argument for preferring them. Although Gulliksen (1950) mentions this property of unstandardized weights, he does not appear to consider it very important.

The results in Table 1 describe an absolute relationship between high-school and college 
Table 1

Effects of Various Levels of Selection on the Independent Variable of High School Grades

\begin{tabular}{|c|c|c|c|c|}
\hline \multirow{2}{*}{ Variable } & \multirow{2}{*}{$\frac{\text { Selected }}{100 \%}$} & \multirow{2}{*}{$\frac{\text { Group }}{80 \%}$} & \multirow{2}{*}{$\frac{\text { Includes }}{50 \%}$} & \multirow{2}{*}{$\frac{\text { Top: }}{20 \%}$} \\
\hline & & & & \\
\hline \multicolumn{5}{|l|}{ High School GPA } \\
\hline Mean & 2.60 & 2.84 & 3.16 & 2.58 \\
\hline S.D。 & .70 & .53 & .42 & .32 \\
\hline \multicolumn{5}{|l|}{ College GPA } \\
\hline Mean & 2.10 & 2.28 & 2.52 & 2.83 \\
\hline S.D. & .80 & .73 & .68 & .65 \\
\hline Correlation between GPAs & .65 & .55 & .46 & .36 \\
\hline \multicolumn{5}{|l|}{ Regression Weights } \\
\hline Standardized & .65 & .55 & .46 & .36 \\
\hline Unstandardized & .74 & .74 & .74 & .74 \\
\hline
\end{tabular}

grades in which the only effect of selection is to eliminate cases. In other words, Table 1 describes a situation in which students who attend highly selective colleges receive exactly the same grades they would have received if those colleges were completely unselective. There should be no confusion about this point; much of the preference for unstandardized weights is based on a search for, and an expectation of finding, relationships that are invariant in precisely this absolute sense. When such absolute relationships in fact exist, unstandardized weights do offer notable advantages. To illustrate these advantages, consider the following example suggested by Kim and Mueller (1976).

Suppose that several companies pursue identical sexually and racially discriminatory policies, so that the rate of pay for their workers is determined by the formula:

Pay Rate $=\$ 10+\$ 2 \times$ Sex $($ Male $=1$, Female=0) $+\$ 3 \times$ Race (White $=1$, Other $=0)+$ $\$ 1 \times$ Years of Experience

Table 2 shows how variations among companies in the sexual composition, racial composition, and experience of their work forces affected the standardized and unstandardized regression weights, relating those variables to pay rate. (It is irrelevant whether these variations were pro- duced by selection or simple sampling variation.) For computational convenience this table assumed no correlation among sex, race, and experience, but this assumption had no effect on the overall pattern of results (Kim \& Mueller, 1976).

The pattern of results is clear. The standardized regression weights (which in this case were equal to the zero-order correlations) for each variable varied not only with changes in its own standard deviation but also with changes in the standard deviations of the other two causal variables. These findings help explain why some writers argue that the percent of variance accounted for by various variables may be of little scientific interest (Duncan, 1975). The unstandardized regression weights, on the other hand, were invariant and, in addition, clearly revealed the underlying causal relationships.

A less important reason for preferring unstandardized weights involves the impact of error variance on the regression weights (Bohrnstedt \& Carter, 1971). Table 3 compares the effects of independent variable error and dependent variable error. Again, the pattern is clear. The correlations and therefore the standardized regression weights were reduced by error variance on either the independent variable or the de- 
Table 2

Standardized and Unstandardized Regression Weights

for Hypothetical Example Suggested by Kim and Mueller

\begin{tabular}{|c|c|c|c|c|c|c|c|c|c|c|c|c|c|}
\hline \multirow{3}{*}{$\begin{array}{l}\text { \%ale/\%hite } \\
\text { and Range in } \\
\text { Years of } \\
\text { Experience }\end{array}$} & \multirow{2}{*}{\multicolumn{2}{|c|}{$\frac{\text { Means }}{\text { Sex }}$}} & 3 and $s$ & \multicolumn{2}{|c|}{ Standard } & \multicolumn{2}{|c|}{ Deviations } & \multicolumn{6}{|c|}{ Regression Weights } \\
\hline & & & Race & \multicolumn{2}{|c|}{$\frac{\text { Standard }}{\text { Exp }}$} & \multicolumn{2}{|c|}{$\frac{\text { Devtal Lons }}{\text { Pay }}$} & \multicolumn{3}{|c|}{$\frac{\text { Standardized }}{\text { Sti }}$} & \multicolumn{3}{|c|}{ Unstandardized } \\
\hline & & $\mathrm{SD}$ & $\mathrm{MSD}$ & $M$ & $\mathrm{SD}$ & $M$ & SD & sex & Race & Exp & Sex & Race & Exp \\
\hline $20 \% / 20 \%$ & & & & & & & & & & & & & \\
\hline $0-6$ & .2 & .4 & .2 .4 & 3.0 & 1.0 & 14.00 & 1.76 & .46 & .68 & .57 & 2.0 & 3.0 & 1.0 \\
\hline $\begin{array}{c}0-12 \\
20 \% / 50 \%\end{array}$ & .2 & .4 & .2 .4 & 6.0 & 2.0 & 17.00 & 2.47 & .32 & .49 & .81 & 2.0 & 3.0 & 1.0 \\
\hline $0-6$ & .2 & .4 & .5 .5 & 3.0 & 1.0 & 14.90 & 1.97 & .41 & .76 & .51 & 2.0 & 3.0 & 1.0 \\
\hline $0-1$ & .2 & .4 & .5 .5 & 6.0 & 2.0 & 17.90 & 2.62 & .30 & .57 & .76 & 2.0 & 3.0 & 1.0 \\
\hline $20 \% / 80$ & & & & & & & & & & & & & \\
\hline $0-6$ & .2 & .4 & .8 .4 & 3.0 & 1.0 & .80 & 1.76 & .46 & .68 & .57 & 2.0 & 3.0 & 1.0 \\
\hline $0-1$ & .2 & .4 & .8 .4 & 6.0 & 2.0 & 18.80 & 2.47 & .32 & .49 & .81 & 2.0 & 3.0 & 1.0 \\
\hline $50 \% /$ & & & & & & & & & & & & & \\
\hline 0 & .5 & .5 & .2 .4 & .0 & 1.0 & .60 & 1.85 & .54 & .65 & .54 & 2.0 & 3.0 & 1.0 \\
\hline $0-12$ & .5 & .5 & & 6.0 & 2.0 & 17.60 & 2.54 & .39 & .47 & .79 & 2.0 & 3.0 & 1.0 \\
\hline $50 \% / 50 \%$ & & & & & & & & & & & & & \\
\hline $0-6$ & .5 & .5 & $.5 \cdot .5$ & 3.0 & 1.0 & 50 & 2.06 & .49 & .73 & .49 & 2.0 & 3.0 & 1.0 \\
\hline $0-12$ & .5 & .5 & .5 .5 & .0 & 2.0 & 18.50 & 2.69 & .37 & .56 & .74 & 2.0 & 3.0 & 1.0 \\
\hline $50 \% / 80 \%$ & & & & & & & & & & & & & \\
\hline & .5 & .5 & .8 .4 & 3.0 & 1.0 & & 1 & .54 & .65 & .54 & 2 & 3.0 & 1.0 \\
\hline 0 & .5 & .5 & .8 .4 & 6.0 & 2.0 & 19.40 & 2.54 & .39 & .47 & .79 & 2.0 & 3.0 & 1.0 \\
\hline $80 \% / 20$ & & & & & & & & & & & & & \\
\hline $0-6$ & .8 & .4 & .2 .4 & 3.0 & 1.0 & 15.20 & 1.76 & .46 & .68 & .57 & 2.0 & 3.0 & $1: 0$ \\
\hline $0-12$ & .8 & .4 & .2 .4 & 6.0 & 2.0 & 18.20 & 2.47 & .32 & .49 & .81 & 2.0 & 3.0 & 1.0 \\
\hline $80 \%$ & & & & & & & & & & & & & \\
\hline 0 & .8 & .4 & .5 .5 & 3.0 & 1.0 & & 1. & .41 & .76 & .51 & 2. & 3.0 & 1.0 \\
\hline $0-12$ & .8 & .4 & .5 .5 & 6.0 & 2.0 & 19.10 & 2.62 & .30 & .57 & .76 & 2.0 & 3.0 & 1.0 \\
\hline $80 \%$ & & & & & & & & & & & & & \\
\hline $0-6$ & .8 & .4 & .8 .4 & 3.0 & 1.0 & & 1 . & .46 & .68 & .5 & & 3.0 & 1.0 \\
\hline $0-12$ & .8 & .4 & .8 .4 & 6.0 & 2.0 & 20.00 & 2.47 & .32 & .49 & .81 & 2.0 & 3.0 & 1.0 \\
\hline
\end{tabular}

pendent variable, while the unstandardized weights varied with independent variable error but were invariant for dependent variable error.

\section{Why Do Ouher Behavioral Scientionts

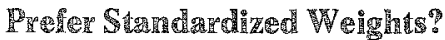

A preference for standardized weights appears to involve facts, convictions, or both with respect to measurement in the behavioral sciences. The most elementary of these facts is that the units of measurement for many scales in the behavioral sciences are arbitrary, and standardized weights are invariant for changes in the units of mea- surement, whereas unstandardized weights are not. These properties of standardized weights are illustrated in Table 4, which shows the effects of changing the units of measurement for a hypothetical constant relationship between the height and weight of, say, behavioral scientists. Proponents of unstandardized weights explicitly recognize these effects of units of measurement (Blalock, 1976; Schoenberg, 1972); indeed, in their emphasis on the importance of "interval" or "ratio" scales, they seem to be the intellectual heirs of Stevens (1946). The example in Table 4 makes it clear, however, that changing 
Table 3

Impact of Measurement

Error on Regression Weights

\begin{tabular}{|c|c|c|c|c|}
\hline \multirow{2}{*}{ Variable } & \multicolumn{4}{|c|}{ S.D. of Error Scores } \\
\hline & 0.00 & 2.50 & 5.00 & 10.00 \\
\hline \multicolumn{5}{|l|}{ Error-Free Variable } \\
\hline Mean & 150.00 & 150.00 & 150.00 & 150.00 \\
\hline S.D. & 20.00 & 20.00 & 20.00 & 20.00 \\
\hline \multicolumn{5}{|l|}{ Error-Prone Variable } \\
\hline Mean & 150.00 & 150.00 & 150.00 & 150.00 \\
\hline S.D. & 10.00 & 10.81 & 11.81 & 14.14 \\
\hline Correlation between Variables & .80 & .78 & .72 & .57 \\
\hline \multicolumn{5}{|l|}{ Regression Weights } \\
\hline Standardized & .80 & .78 & .72 & .57 \\
\hline \multicolumn{5}{|c|}{ Unstandardized for Error-Prone } \\
\hline Independent Variable & 1.60 & 1.50 & 1.28 & .80 \\
\hline Dependent Variable & .40 & .40 & .40 & .40 \\
\hline
\end{tabular}

the units of measurement could produce large changes in the unstandardized weights even if interval or ratio scales were achieved. Similar but more complex problems of scale invariance might arise in a very obscure form (Bentler, 1977, 1976, 1980; Krane \& McDonald, 1978) in studies that use latent variable procedures, such as those incorporated in the LISREL computer package (Jöreskog \& Sörbom, 1978).

Table 4

Impact of Units of Measurement on Regression Weights for Hypothetical Relationship between Height and Weight

\begin{tabular}{|c|c|c|c|c|}
\hline \multirow[b]{2}{*}{ Variable } & \multicolumn{4}{|c|}{ Measures of Height and Weight } \\
\hline & $\begin{array}{l}\text { Feet } \\
\text { Pounds }\end{array}$ & $\begin{array}{l}\text { Inches } \\
\text { Ounces }\end{array}$ & $\begin{array}{l}\text { Meters } \\
\text { Kilograms }\end{array}$ & $\begin{array}{l}\text { Centimeters } \\
\text { Grams }\end{array}$ \\
\hline \multicolumn{5}{|l|}{ Height } \\
\hline Mean & 5.75 & 69.00 & 1.75 & 175.26 \\
\hline S.D. & 0.50 & 6.00 & 0.15 & 15.24 \\
\hline \multicolumn{5}{|l|}{ Weight } \\
\hline Mean & 165.00 & 2640.00 & 74.84 & 74842.78 \\
\hline$S . D$. & 15.00 & 240.00 & 6.80 & 6803.88 \\
\hline \multicolumn{5}{|l|}{ Height-Weight } \\
\hline Correlation & .60 & .60 & .60 & .60 \\
\hline $\begin{array}{l}\text { Weights for Regression } \\
\text { of Weight on Height }\end{array}$ & & & & \\
\hline Standardized & .60 & .60 & .60 & .60 \\
\hline Unstandardized & 18.00 & 24.00 & 26.79 & 267.87 \\
\hline
\end{tabular}


vick, 1968). More concretely, proponents of standardized weights are likely to believe that the grades college students receive depend on how they compare with other students currently attending their college, not their absolute performance; so, in general, students in highly selective colleges will not receive exactly the same grades they would have received in unselective colleges.

Table 5 illustrates the effects of explicit selection on high-school grades if college grades are relative rather than absolute. This example assumed that the underlying relationship (i.e., the relationship in the unselected case) was exactly the same as the example in Table 1. Moreover, the correlation in the unselected case measured the finest valid discrimination that college faculty members could make in rank ordering the performance of their students, so the correlation between high-school and college GPAs changed with selection in exactly the same way as shown in Table 1. However, faculties at all colleges assigned the same proportion of $A$ 's, $\mathbb{R}^{\prime}$ 's, $C$ 's, and so forth, to the performance of whatever students they had, so the mean and standard deviation of college grades were invariant under selec. tion. The available evidence suggests that Table 5 is much closer to the real world than Table 1; although some variation in grades among col- leges exists, this variation is much smaller than would be the case if an absolute standard of grading existed (Astin, 1971).

The portrayed invariance in the mean and standard deviation of GPAs at colleges differing in selectivity probably can best be viewed as a special case of changes in the units of measurement. Therefore, Table 5 portrays the combined effects of selection on the independent variable and changes in the criterion units of measurement. The pattern is quite clear; neither the standardized weights nor the unstandardized weights were invariant. But consider what would happen if the formulas presented in Gulliksen (1950) were used to adjust for the effects of selection. The adjusted standardized weights would be invariant, whereas the adjusted unstandardized weights would vary substantially. The invariance in the adjusted standardized weights would indicate that the underlying rank order relationship between high-school grades and college grades was invariant, and it should be emphasized that this type of invariance would be just as scientifically meaningful as the invariance in unstandardized weights shown in Table 1. The variation in the adjusted unstandardized weights also would convey scientifically meaningful information, namely, that colleges differed in grading standards.

Table 5

Effects of Various Levels of Selection

on the Independent Variables of High School Grades

When College Grades are Relative Rather than Absolute

\begin{tabular}{|c|c|c|c|c|}
\hline \multirow{2}{*}{ Variable } & \multirow{2}{*}{$\begin{array}{l}\text { Selected } \\
100 \%\end{array}$} & Group & \multicolumn{2}{|c|}{ Includes Top: } \\
\hline & & $80 \%$ & $50 \%$ & $20 \%$ \\
\hline \multicolumn{5}{|l|}{ High School GPA } \\
\hline Mean & 2.60 & 2.84 & 3.15 & 3.50 \\
\hline S.D. . & .70 & .53 & .42 & .32 \\
\hline \multicolumn{5}{|l|}{ College GPA } \\
\hline Mean & 2.10 & 2.10 & 2.10 & 2.10 \\
\hline$S . D$. & .80 & .80 & .80 & .80 \\
\hline Correlation between GPAs & .65 & .55 & .46 & .36 \\
\hline \multicolumn{5}{|l|}{ Regression Weights } \\
\hline Standardized & .65 & .55 & .46 & .36 \\
\hline Unstandardized & .74 & .82 & .87 & .91 \\
\hline
\end{tabular}

Downloaded from the Digital Conservancy at the University of Minnesota, http://purl.umn.edu/93227. May be reproduced with no cost by students and faculty for academic use. Non-academic reproduction requires payment of royalties through the Copyright Clearance Center, http://www.copyright.com/ 
In a criticism of unstandardized weights, Green (1977) has invoked the similar case of changes in the length (e.g., number of items) of a test or other behavioral science measure. The effects of test length have long been considered important (Horst, 1948), especially in the argument that test length should be considered when comparing validities (Cronbach \& Glesser, 1968 ), and because standard corrections for unreliability estimate the values that would be obtained if the measure(s) were made infinitely long. Therefore, Table 6 illustrates the effects of changes in the length of the independent and dependent variables for hypothetical data in which all items measure exactly the same trait, have exactly the same distribution of item "difficulties" (that is, proportion of the population giving the scored response), and so on. The pattern, again, is clear; both the standardized and unstandardized weights changed as test length changed (Green, 1977), although the unstandardized weights did vary directly with changes in the length of the dependent variable.

\section{Other difects of Selection on Regression Wengh}

There are (at least) two other important conditions that can affect regression weights, mamely, explicit selection on the dependent variable and explicit selection on a mediating variable. Any circumstance that produces missing data, such as nonresponse to follow-ups in longitudinal studies, involves such selection, and a listwise deletion for missing data is likely to involve a complex pattern of selection on independent, mediating, and dependent variables. Also, researchers sometimes deliberately select on a mediating or dependent variable. For example, researchers studying status attainment commonly limit their analyses to employed persons, researchers studying contraceptive behavior sometimes limit their analyses to married persons, and researchers studying the impact of schooling sometimes limit their analyses to students in particular "tracks," or at best compare students assigned nonrandomly to different tracks.

Colleges with opern admissions policies can illustrate the effects of explicit selection on the dependent variable. In the pure case, no selection at all on high-school grades takes place in such colleges, but students who receive low college grades are eliminated because they withdraw, are flumked out, and so forth. This selection directly reduces the standard deviation of college GPAs and indirectly reduces both the correlations between high-school and college GPAs and the standard deviation of high-school GPAs. Table 7 illustrates the impact of various levels of explicit selection on the dependent variable of college GPAs when the underlying relationship in the unselected case again was the same as that portrayed in Table 1. This example, of course, again assumed an absolute relationship between high-school and college GPAs.

The pattern of results for the correlations and standardized regression weights followed the pattern shown in Table 1, but the pattern of results for the unstandardized regression weights was quite different in that these weights were strongly affected by selection on the dependent variable. Indeed, as the last two rows in this table indicate, the unstandardized weights were affected more than the standardized weights. Contrary to what some methodologists (Schoenberg, 1972) have suggested, therefore, a finding that the unstandardized weights for two groups differ more than the standardized weights may be substantively unimportant, indicating only that the two groups differ in degree of selection on the dependent variable. An analysis reported elsewhere (Richards, 1979) found that the effects of selection on the dependent variable for the $\mathbb{K}$ im and Mueller (1976) illustration shown in Table 2 were more complex than, but generally confirmed, the effects shown in Table 7.

The reasons for the differences between Table 1 and Table 7 are easy to understand if it is recalled that the relationship between two variables includes two regressions and it is realized that what is invariant under selection is the (un. 
Table 6

Impact of Changes in Test Length on Regression Weights

\begin{tabular}{|c|c|c|c|c|}
\hline \multirow[t]{2}{*}{ Variable } & \multicolumn{4}{|c|}{$\begin{array}{l}\text { Number of Items } \\
\text { in Changed Variable }\end{array}$} \\
\hline & 80 & 40 & 20 & 10 \\
\hline \multicolumn{5}{|l|}{ Unchanged Variable } \\
\hline Mean & 150.00 & 150.00 & 150.00 & 150.00 \\
\hline S.D. & 20.00 & 20.00 & 20.00 & 20.00 \\
\hline \multicolumn{5}{|l|}{ Changed Variable } \\
\hline Mean & 40.00 & 20.00 & 10.00 & 5.00 \\
\hline$S . D$. & 10.00 & 5.48 & 3.16 & 1.94 \\
\hline \multicolumn{5}{|l|}{ Correlation between } \\
\hline Variables & .80 & .73 & .63 & .52 \\
\hline \multicolumn{5}{|l|}{ Regression Weights } \\
\hline Standardized & .80 & .73 & .63 & .52 \\
\hline \multirow{2}{*}{\multicolumn{5}{|c|}{$\begin{array}{l}\text { Unstandardized for } \\
\text { Changed: }\end{array}$}} \\
\hline & & & & \\
\hline Independent Variable & 1.60 & 1.43 & 1.26 & 1.04 \\
\hline Dependent Variable & .40 & .20 & .10 & .05 \\
\hline
\end{tabular}

standardized) regression of the incidental selection variable on the explicit selection variable. Therefore, the regression of the independent variable on the dependent variable is invariant under explicit selection on the dependent vari- able. Unfortunately, this is the wrong regression for making causal inferences from regression weights; such inferences necessarily involve the regression of the dependent variable on the independent variable.

Table 7

Effects of Various Levels of Selection on the Dependent Variable of College Grades

\begin{tabular}{lrrrr}
\hline Variable & \multicolumn{4}{c}{ Surviving Group Includes } \\
\cline { 2 - 5 } & $100 \%$ & $80 \%$ & $50 \%$ & $20 \%$ \\
\hline High School GPA & & & & \\
$\quad$ Mean & 2.60 & 2.76 & 2.97 & 2.24 \\
S.D. & .70 & .64 & .60 & .57 \\
College GPA & & & & \\
$\quad$ Mean & 2.10 & 2.37 & 2.74 & 3.22 \\
$\quad$ S.D. & .80 & .61 & .48 & .36 \\
Correlation between GPAs & .65 & .55 & .46 & .36 \\
Regression Weights & & & & \\
$\quad$ Standardized & .65 & .55 & .46 & .36 \\
$\quad$ Unstandardized & .74 & .53 & .37 & .23 \\
Population/Surviving Group & & & & \\
Regression Weight Ratios & & & & \\
$\quad$ Standardized & 1.00 & 1.19 & 1.42 & 1.79 \\
$\quad$ Unstandardized & 1.00 & 1.41 & 2.03 & 3.20 \\
\hline
\end{tabular}

Downloaded from the Digital Conservancy at the University of Minnesota, http://purl.umn.edu/93227. May be reproduced with no cost by students and faculty for academic use. Non-academic reproduction requires payment of royalties through the Copyright Clearance Center, http://www.copyright.com/ 


\section{Figure 1}

Path Diagram of Relationships Among

High-School Grades, College Grades, and College Graduation

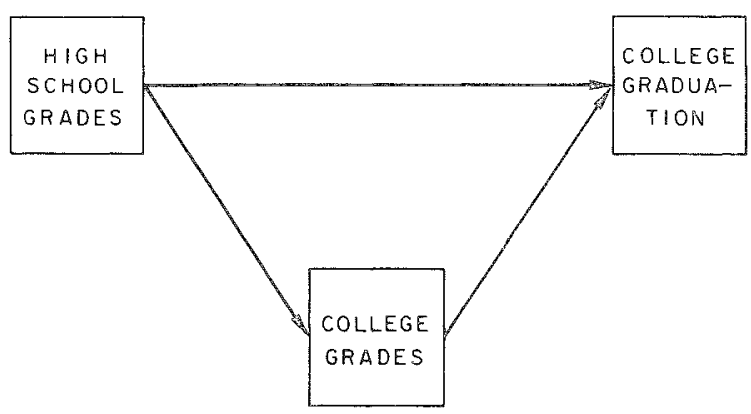

The final condition to be discussed involves explicit selection on a mediating variable. College selection also can illustrate this condition if the additional variable of college graduation is considered. That is, the relationship between high-school GPA and college graduation is mediated through college GPAs; thus in open admissions colleges the elimination of students with low college grades constitutes explicit selection on a mediating variable. If these relationships are placed in a path analytic context, they can be described by the path diagram shown in Figure 1. (Because residual or disturbance variables are irrelevant to the present discussion, they are omitted from this diagram.) Accordingly, Table 8 adds hypothetical data for graduation to the college selection example in Tables $\mathbb{1}$ and 7 , choosing the mean and standard deviation for college graduation to reflect findings that about half of those (white) students who go to college graduate (Galloway \& Noell, 1978).
The relationships among high-school GPA, college GPA, and college graduation then were analyzed for various levels of explicit selection on college GPAs, following the path diagram in Figure 1 and using the procedures described by Alwin and Hauser (1975) to decompose the relationship between high-school GPA and college graduation into total, direct, and indirect components. Results are shown in Table 9.

The pattern is fairly complex. The standardized weights, or path coefficients, for the rellationship between college GPA and graduation changed with varying degrees of selection, whereas the unstandardized weights, or path regression coefficients, were invariant. The unstandardized weights for the direct effect of high-school GPA were also invariant, and the standardized weights changed very little, actually increasing slightly. Most importantly, both the standardized and unstandardized weights for the total and indirect effects of high-school

Table 8

Hypothetical Means, Standard Deviations, and Intercorrelations for Relationships among High School GPA, College GPA, and College Graduation

\begin{tabular}{lccccc}
\hline Variable & \multicolumn{5}{c}{ Variable } \\
\cline { 2 - 5 } & 1 & 2 & 3 & Mean & S.D. \\
\hline High School GPA & - & & & 2.60 & 0.70 \\
College GPA & .65 & $-\infty$ & & 2.10 & 0.80 \\
College Graduation & .60 & .70 & $\ldots$ & 0.50 & 0.50 \\
\hline
\end{tabular}

Downloaded from the Digital Conservancy at the University of Minnesota, http://purl.umn.edu/93227. May be reproduced with no cost by students and faculty for academic use. Non-academic reproduction requires payment of royalties through the Copyright Clearance Center, http://www.copyright.com/ 


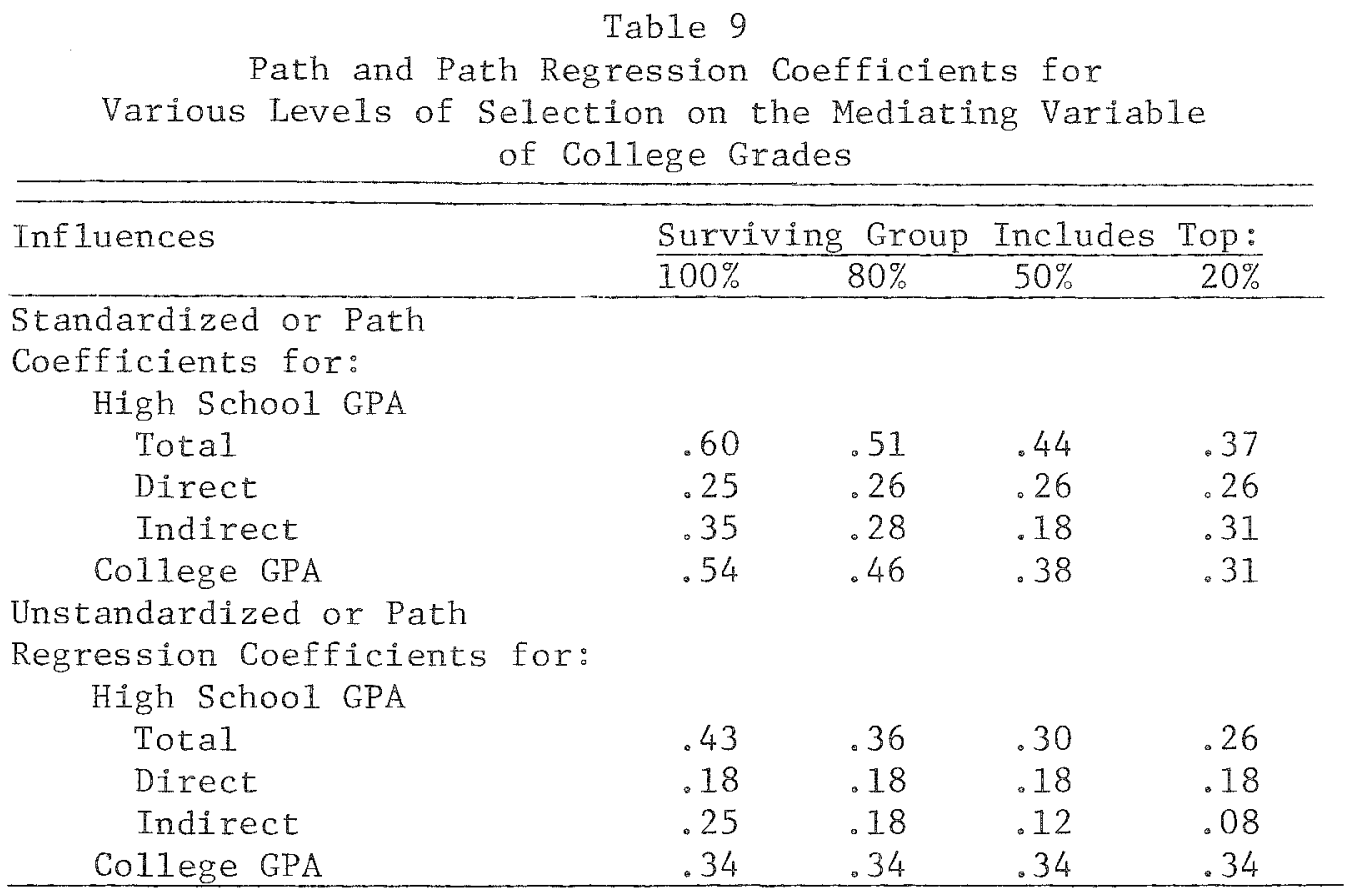

GPA were strongly affected by explicit selection on the mediating variable of college GPA. The ratio of indirect to direct effects also were strongly affected. Such effects would be more complex and obscure for a more complicated path model.

The results in Tables 7 and 8 are relevant to a procedure suggested by some methodologists (Fligstein \& Wolf, 1978; Heckman, 1974) for correcting for missing dependent variable data. This procedure involves developing a dummy criterion variable $(0=$ data missing; $1=$ data present), regressing this dummy variable on appropriate independent variables with all cases included, and using the regression weights to compute a predicted score on this dummy criterion for each case. These predicted scores, unlike the dummy criterion scores, would be continuously distributed and could be interpreted as measuring the probability that a given case would have dependent variable data. (These methodologists suggest a probit analysis, but this methodological nicety appears to be an unnecessary complication. An ordinary regression analysis of the dummy criterion should yield completely equivalent results.)

However, these methodologists then propose treating such predicted scores as just another antecedent variable in the main regression analysis for cases with scores on the dependent variables. This procedure appears inadequate for controlling the effects of missing dependent variable data. A more appropriate control would be to treat the predicted scores as a mediating variable subject to explicit selection, using the formulas presented by Gulliksen (1950) to adjust for the effects of this selection.

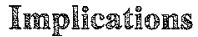

The goal of this review was to clarify uses of standardized versus unstandardized regression weights by illustrating the strengths of each. To some extent, this goal has been achieved. Standardized, but not unstandardized, weights are invariant over changes in the units of measurements; unstandardized, but not standardized, weights are invariant when selection or sampling 
variation occurs on the independent variable and when dependent variable measurement error is present. More basically, however, the major thrust of the examples reported here is to reinforce earlier doubts (Campbell \& Erlebacher, 1975; Cook \& Campbell, 1976, pp. 254-288; Gilbert, Mosteller, \& Tukey, 1976) about the scientific usefulness of any regression weights in nonrandomized, quasi-experimental situations. Neither kind of weight is invariant when independent variable measurement error is present, when measurement is relative to a norm rather than absolute, when test length changes, or when selection occurs on the dependent variable. Also, neither kind is very satisfactory when selection occurs on a mediating variable.

In short, several circumstances that could affect regression weights were examined, and most of these circumstances affected both standardized and unstandardized regression weights, sometimes quite strongly. Thus, neither kind of weight appears particularly robust; neither kind can be recommended unequivocally for comparing groups; and certainly neither kind appears to provide a panacea for overcoming the problems of analyzing behavioral data.

\section{聚efferes}

Alwin, D. F., \& Hauser, R. M. The decomposition of effects in path analysis. American Sociological Review, $1975,40,37-42$.

American College Testing Program. College student profiles. Iowa City IA: Author, 1966.

Astin, A. W. Predicting academic performance in college: Selectivity data for 2,300 American colleges. New York NY: Free Press, 1971.

Bentler, P. M. Multistructure statistical model applied to factor analysis. Multivariate Behavioral Research, 1976, 11, 3-25.

Bentler, P. M. Factor simplicity index and transformations. Psychometrika, 1977, 42, 277-295.

Bentler, P. M. Multivariate analysis with latent variables: Causal modeling. Annual Review of Psy. chology, 1980, 31, 419-456.

Blalock, H. M., Jr. Causal inferences in nonexperimental research. Chapel Hill $\mathrm{NC}$ : University of North Carolina Press, 1964.
Blalock, H. M., Jr. Path coefficients versus regression coefficients. American Sociological Review, 1967, $32,675-676$.

Blalock, H. M., Ir. The measurement problem: A gap between the language of theory and research. In H. M. Blalock, Jr. \& A. B. Blalock (Eds.), Methodology in social research. San Francisco CA: JosseyBass, 1968.

Blalock, H. M., Ir. Can we find a genuine ordinal slope analogue? In D. R. Heise (Ed.), Sociological methodology 1976. San Francisco CA: JosseyBass, 1976.

Bohrnstedt, G. W. Observations on the measurement of change. In E. Borgatta (Ed.), Sociological methodology 1969. San Francisco CA: Jossey-Bass, 1969.

Bohrnstedt, G. W., \& Carter, T. M. Robustness in regression analysis. In H. L. Costner (Ed.), Sociological methodology 1971. San Francisco CA: Jossey-Bass, 1971.

Campbell, D. T., \& Erlebacher, A. How regression artifacts in quasi-experimental evaluations can mistakenly make compensatory education look harmful. In E. L. Struening \& M. Guttentag (Eds.), Handbook of evaluation research. Beverly Hills CA: Sage Publications, 1975.

Cook, T. D., \& Campbell, D. T. The design and conduct of quasi-experiments and true experiments in field settings. In M. D. Dunnette (Ed.), Handbook of industrial and organizational psychology. Chicago IL: Rand McNally, 1976.

Cronbach, L. I., \& Gleser, G. Psychological tests and personnel decisions. Urbana: University of Illinois Press, 1968.

Duncan, 0 . D. Introduction to structural equation models. New York NY: Academic Press, 1975.

Fligstein, N., \& Wolf, W. Sex similarities in occupational status attainment: Are the results due to restriction of the sample to employed women? Social Science Research, 1978, 7, 197-212.

Galloway, M. A., \& Noell, J. The condition of education. Washington DC: National Center for Educational Statistics, 1978 .

Ghiselli, E. E. Theory of psychological measurement. New York NY: McGraw-Hill, 1964.

Gilbert, I. P., Mostellar, F., \& Tukey, J. Steady social progress requires quantitative evaluation to be searching. In $C$. C. $A b t(E d$.$) , The evaluation of$ social programs. Beverly Hills CA: Sage Publications, 1976.

Green, B. Parameter sensitivity in multivariate methods. Multivariate Behavioral Research, 1977, $12,263-287$.

Gulliksen, H. Theory of mental tests. New York NY: John Wiley \& Sons, 1950. 
Hargens, L. L. A note on standardized coefficients as structural parameters. Sociological Methods and Research, 1976, 5, 247-256.

Heckman, J. Shadow prices, market wages, and labor supply. Econometrica, 1974, 42, 679-694.

Horst, $P$. Regression weights as a function of test length. Psychometrika, 1948, 13, 125-134.

Jöreskog, K. G., \& Sörbom, D. LISREL users manual: Version IV (Release 2). Chicago IL: National Educational Resources, 1978.

Kim, J., \& Mueller, C. W. Standardized and unstandardized coefficients in causal analysis. Sociological Methods and Research, 1976, 4, 423-437.

Krane, W. R., \& McDonald, R. P. Scale invariance and the factor analysis of correlation matrices. British Journal of Mathematical and Statistical Psychology. 1978, 31, 218-228.

Linn, R. L. Range restriction problems in the use of self-selection groups for test validation. $P_{s y-}$ chological Bulletin, 1968,69, 69-73.

Lord, F. M., \& Novick, M. R. Statistical theories of mental test scores. Reading MA: Addison-Wesley, 1968.

Richards, I. M., Jr. Regression weights and communication among researchers from different disciplines (Research Report No. 283). Baltimore MD: The Johns Hopkins University, Center for
Social Organization of Schools, 1979. (ERIC Document Reproduction Service No. ED 184914)

Schoenberg, R. Strategies for meaningful comparisons. In H. C. Costner (Ed.), Sociological methodology 1972. San Francisco CA: Jossey-Bass, 1972.

Stevens, S. S. On the theory of scales of measurement. Science, 1946, 103,670-680.

\section{Acknowledgriments}

This research was supported by funds granted to the Center for Social Organization of Schools. The Johns Hopkins University, by the National Institute of Education. The opinions expressed do not necessarily reflect the position or policy of the National Institute of Education, and no official endorsement by the $\mathrm{Na}$ tional Institute of Education should be inferred.

\section{Aathorer" Address}

Send requests for reprints or further information to James M. Richards, Jr., Office of Educational Development, School of Medicine, University of Alabama in Birmingham, Birmingham AL 35294. 